\title{
SINKRETISME SIWA-BUDDHA DALAM LONTAR CANDRA BHERAWA
}

Oleh:

\section{Nyoman Ariyoga}

ariyoga@stahnmpukuturan.ac.id

\author{
Sekolah Tinggi Agama Hindu Negeri Mpu Kuturan \\ Singaraja
}

Proses Review 9-16 Maret, Dinyatakan Lolos 20 Maret

\begin{abstract}
Based on the historical history of Indonesian culture, the development of Hinduism and Buddhism in Indonesia entered into the classical period. This is still stored in religious literature which in ancient times, these values were contained in lontar. Lontar is a classical library containing ethical, aesthetic, and religious values. These values serve as guidelines in living life, how to organize the socio-religious order in Bali. One of the Hindu religious heritages in the form of Lontar Parwa is Lontar Candra Bherawa, which is a classic literary work that has a lot of knowledge of Hindu religious teachings, both in the form of tattwa, morality, and also ceremonies which are still very relevant to be implemented in people's lives. In addition, Lontar Candra Bherawa contributed stories about the concept of ShivaBuddha divinity which became the momentum for the union of these two teachings, which had once become a concept of religious divinity in the Indonesian archipelago. The Shiva-Buddha teachings influence each other so that there is a close and familial relationship. In Lontar Candra Bherawa, the relationship is reaffirmed that the two teachings lead to the same source, namely Shiva-Buddha, which is single. This research is a textual study, which uses text as the main source. This was done solely to find out the mindset and chronology of Hindu thought in the past. As in Lontar Candra Bherawa, there is a concept of Shiva-Buddha syncretism that once gave birth to major civilizations in the archipelago.
\end{abstract}

Keywords: Syncretism, Shiva-Buddha, Lontar Candra Bherawa

\begin{abstract}
Abstrak
Berdasarkan pembabakan sejarah kebudayaan Indonesia maka perkembangan Hindu dan Buddha di Indonesia masuk ke dalam masa klasik. Hal ini masih tersimpan dalam karya sastra keagamaan yang pada jaman dahulu, nilai-nilai tersebut dimuat dalam lontar. Lontar merupakan pustaka klasik yang mengandung nilai-nilai etis, estetis, dan religius. Nilai-nilai ini sebagai pedoman dalam menjalani kehidupan, bagaimana menata tatanan sosial keagamaan di Bali. Salah satu
\end{abstract}


warisan agama Hindu berupa Lontar Parwa adalah Lontar Candra Bherawa adalah suatu karya sastra yang tergolong klasik memiliki banyak pengetahuan ajaran-ajaran Agama Hindu, baik dalam bentuk ajaran tattwa, susila, maupun juga upacara yang masih sangat relevan diimplementasikan dalam kehidupan masyarakat. Selain itu Lontar Candra Bherawa memberikan kontribusi cerita mengenai konsep ketuhanan Siwa-Buddha yang menjadi momentum bersatunya kedua paham ajaran ini, yang pernah menjadi sebuah konsep kepercaaan agama di bumi Nusantara Indnesia. Ajaran Siwa-Buddha saling memberikan pengaruh sehingga terjadi hubungan yang erat dan kekeluargaan. Dalam Lontar Candra Bherawa hubungan tersebut ditegaskan kembali bahwa kedua ajaran tersebut menuju sumber yang sama yaitu Siwa-Buddha adalah tunggal adanya. Penelitian ini merupakan penelitian tekstual, yakni menggunakan teks sebagai sumber utama. Hal ini dilakukan semata untuk mengetahui pola pikir dan kronologis pemikiran umat Hindu pada masa silam. Sebagaimana dalam Lontar Candra Bherawa terdapat konsep ajaran sinkretisme Siwa-Buddha yang pernah melahirkan peradaban-peradaban besar di nusantara.

Kata Kunci: Sinkretisme, Siwa-Buddha, Lontar Candra Bherawa

\section{PENDAHULUAN}

Berdasarkan pembabakan sejarah kebudayaan Indonesia maka perkembangan Hindu dan Buddha di Indonesia masuk ke dalam masa klasik. Periode masa klasik sendiri berlangsung dari abad 4-16 masehi. Selama rentang waktu berabad-abad tersebut terjadi perkembangan dalam berbagai bidang seni yang sangat pesat baik dalam bidang arsitektur atau seni rupa, seni suara, seni tari, dan seni sastra. Adanya sebuah karya, baik seni bangunan maupun karya sastra keagamaan merupakan salah satu tolak ukur berkembangya sebuah kebudayaan dalam suatu daerah karena dua unsur tersebut mampu mewakili serta memberikan gambaran tentang unsur-unsur dasar dari sebuah kebudayaan seperti agama, politik, sistem sosial masyarakat, bahasa, mata pencarian penduduk, sistem pengetahuan serta teknologi yang berkembang (Adnyana, 2013:15).

Pada prinsipnya agama Hindu diwariskan secara turun-temurun baik dengan cara lisan maupun dengan melaui tulisan. Namun di dalam penulisan suatu kitab ataupun Lontar, penulis tidak mau menyebutkan namanya. Hal ini terbukti dengan adanya Lontar-Lontar tanpa menyebutkan nama pengarangnya. Sebagaimana dimaklumi Lontar-Lontar itu merupakan pegangan bagi umat Hindu yang dapat menuntun seseorang agar dapat bertingkah laku yang baik dan benar, belajar melalui Lontar pula seseorang bisa menjadi wiku, pendeta, balian sonteng yang menjadi pengayom di masyarakat.

Karya sastra kuno pada mulanya hanya dimuat dalam bentuk lontar, dan kebanyakan masyarakat menganggap bahwa lontar adalah benda sakral yang tidak sembarangan dilihat dan dibaca. Sebab diyakini bahwa di dalam karya sastra kuno tersebut terdapat kekuatan magis. Sehingga banyak masyarakat khususnya di Bali hanya sebatas memahami lontar sebagai pustaka warisan berisikan ajaran-ajaran Agama yang disucikan, sehingga hanya disimpan dan diupacarai pada hari-hari suci tertentu tanpa berani membacanya karena takut akan kesakralanya. Disamping kondisi lontar yang rentan terhadap cuaca, kondisi tersebut tidaklah menjadi alasan untuk tidak mempelajari isi lontar. Lontar-lontar yang sarat dengan pengetahuan baik tattwa, susila, upacara dan lainya sebagai ekspresi rasa bhakti dan pengabdian kepada Tuhan yang merupakan bagian dari ajaran Agama Hindu. Menurut Suarka (2012:76) lontar merupakan sastra keagamaan sehingga sarat dengan nilai-nilai pendidikan yang salah satu fungsinya adalah untuk meningkatkan harkat dan martabat manusia. Ada berbagai jenis lontar sesuai dengan bentuk, isi, dan judulnya seperti: Lontar Babad, Lontar Kanda, Lontar Kalpasutra, Lontar Kakawin, Lontar Mantra Astawa, Lontar Pala Kerta, Lontar Parwa, Lontar Wariga, Lontar Usada, dan lain sebagainya.

Salah satu warisan agama Hindu berupa Lontar Parwa adalah Lontar Candra Bherawaa 
dalah suatu karya sastra yang tergolong klasik memiliki banyak pengetahuan ajaran-ajaran Agama Hindu, baik dalam bentuk ajaran tattwa, susila, maupun juga upacara yang masih sangat relevan diimplementasikan dalam kehidupan masyarakat. Selain itu Lontar Candra Bherawa memberikan kontribusi cerita mengenai konsep ketuhanan Siwa-Buddha yang menjadi momentum bersatunya kedua paham ajaran ini, yang pernah menjadi sebuah konsep kepercaaan agama di bumi Nusantara Indnesia.

Kitab ini memiliki penanaman konsep, penanaman pengertian atau difinisi dan penanaman akan ajaran agama yang berbeda dalam jalinan peristiwa. Disamping hal tersebut, juga mempertegas dan memberikan kesan mendalam pada pembaca dan pendengar tentang manfaat yang didapatkan dari ajaran Siwa-Buddha. Bukan dalam konteks ini saja, pembaca dan pendengar akan diajak untuk masuk dalam alur prismatis yakni sebuah alur dimana pembaca dan pendengar sendiri yang akan menemukan kebijaksanaan lewat jabaran citra atau karakter yang ditampilkan dari setiap tokoh maharaja Yudistira dan Catur Pandawa serta tokoh maharaja Candra Bherawa. Oleh sebab itu, betapa penting dan istimewanya Lontar Candra Bherawa ini dipelajari serta dihayati ajaranya.

Perbedaan paham Siwa dan Buddha dalam Lontar Candra Bherawa menjadikan konflik diantara masing-masing penganut paham tersebut. Satu sisi tokoh dari maharaja Yudistira dan Catur Pandawa adalah pemuja Sang Hyang Siwa yang sangat teguh. Sedangkan dari tokoh maharaja Candra Bherawa adalah pemuja Sang Hyang Adi Buddha yang sangat teguh. Pada akhirnya terjadilah peperangan dalam menunjukan keteguhan dharma.

Bijaksana, kuat dan teguh, pantang menyerah, penuh pengetahuan, dan tidak sabaran, serta yang lainnya semuanya terwakili dalam setiap karakterisasi maharaja Yudistira, Catur Pandawa dan maharaja Candra Bherawa. Saling menunjukan keteguhan dharma yang dipegang dan dipercayai sebagai tujuan tertinggi. Hal ini membuktikan bahwa untuk mendapatkan sebuah kebenaran harus dilakukan dengan cara pembuktian melalui usaha-usaha yang bisa diterima oleh orang banyak. Namun hakekatnya ajaran Siwa dan Buddha itu saling melengapi satu sama lain. Tidak sempurnalah jika seseorang yang membangun jalan spiritual hanya teguh menjalankan ajaran Siwa melalui Karma Sanyasa, begitu pula sebaliknya tidaklah sempurna bila seseorang hanya teguh menjalankan ajaran Buddha melalui Yoga Sanyasa. Kesatuan konsep ajaran Siwa-Buddha tidak dapat terpisahkan seperti yang di perlihatkan dalam narasi Lontar Candra Bherawa yang kedua paham tersebut lebur dalam sinkretisme Siwa-Buddha.

Citra-citra dari setiap tokoh ini dipergunakan oleh rakawi tanah Bali, untuk mewakili ajaran serta pendidikan Agama Hindu. Jadi pendidikan yang dimaksudkan dalam penelitian ini adalah sebuah proses pendewasaan manusia mengenai pola pikir, perkataan hingga tingkah lakunya, yang kemudian menimbulkan sebuah kesadaran akan jati diri dan menumbuh kembangan sebuah kebijaksanaan akan afeksi moralitas dan kesadaran akan Tuhan Yang Maha Esa. Dalam hal ini, sinkretisme Siwa-Buddha merupakan salah satu konsep ajaran yang memiliki kesamaan tujuan, yaitu manuju kemanunggalan dengan Brahman atau Tuhan Yang Maha Esa dan melenyapkan keterikatan dengan hal-hal duniawi.

\section{METODE PENELITIAN}

Metode penelitian merupakan suatu usaha untuk menemukan, mengembangkan dan menguji kebenaran suatu pengetahuan (Kaelan, 2012:4). Penelitian ini merupakan penelitian tekstual, yakni menggunakan teks sebagai sumber utama. Hal ini dilakukan semata untuk mengetahui pola pikir dan kronologis pemikiran umat Hindu pada masa silam. Demikian pula, jenis penelitian ini adalah jenis penelitian deskriptif dengan menggunakan pendekatan penelitian kualitatif. Pertama, aktualisasi dari langkah kerja penelitian deskriptif dengan menggunakan pendekatan penelitian kualitatif. Sebagaimana jenis penelitian deskriptif merupakan jenis penelitian yang berusaha menggambarkan dan menginterprestasikan objek sesuai dengan apa adanya. Kedua, langkah selanjutnya ialah naskah terpilih, teksnya kemudian dibaca berulang-ulang dengan tujuan 
untuk memberikan penghayatan serta pemberian gambaran peneliti. Dengan demikan peneliti dimungkinkan untuk mengungkapkan isi karya sastra secara maksimal. Ketiga, pembacaan secara struktural tersebut di atas, dipandang mempemudah kearah pelacakan intertekstualitas. Artinya untuk menemukan struktur karya sastra Lontar Candra Bherawa Sebagaimana, Fananie (2002:112) mengemukakan bahwa pendekatan objektif adalah pendekatan yang mendasarkan pada suatu karya sastra secara keseluruhan. Pendekatan yang dinilai dari eksistensi sastra itu sendiri berdasarkan konvensi sastra yang berlaku. Dalam rangka mendapatkan makna kata-kata terpilih, ungkapan tertentu yang khas dan jalan cerita dalam Lontar Candra Bherawa secara oprasional ungkapan yang di pandang sarat makna dikaji dengan menerapkan metodenya teori hermeneutik. Pengetahuan yang didapatkan dari kalimat-kalimat yang sudah di tapsirkan maknanya akan memberikan asumsi baru dalam pikiran. Ini dapat di ungkap dengan metodenya teori kontruktivistik.

\section{III . PEMBAHASAN}

\subsection{Konsep Sinkretisme Siwa-Buddha}

Penelusuran etimologi terhadap kata sinkretisme menurut Anceise OxforDictionary, sinkretisme adalah upaya untuk menenggelamkan berbagai perbedaan dan menghasilkan kesatuan di antara berbagai sekte atau aliran filsafat. (Diartha Nida, 2003:17).

Sinkretisasi Siwa-Buddha di Bali dimaksudkan sebagai penggabungan, percampuran perpaduan sebagai akibat persinggungan atau kontak budaya dengan menenggelamkan berbagai perbedaan dan menghasilkan kesatuan di antara berbagai sekte atau aliran filsafah agama dan kepercayaan Siwa-Buddha di Bali.

Ajaran Siwa dan Buddha secara umum di Indonesia telah terjadi sinkritisme yang saling memberikan kontribusi terhadap kedua ajaran itu. Hal ini merupakan suatu keunikan yang dapat disaksikan di Indonesia khususnya di Bali. Penghormatan terhadap Siwa dan Buddha terjadi begitu luluh dan seolah-olah tidak ada perbedaan sedikitpun. Seperti kutipan berikut yang dapat dikutipkan dari Kakawin Sutasoma pupuh 139 bait 5 sebagai berikut:

Rwāneka dhatu winuwus wara Buddha Wiśwa. Bhinneka rakwa ring apan kěna parwanosěn. Mangkāng jinatwa kalawan Śiwatwa tunggal. Bhinneka tunggal ika tana hana Dharma mangrwa

\section{Terjemahan:}

Disebutkan dua pewujudan beliau itu Buddha dan Siwa. Berbeda konon, tapi kapan dapat dibagi dua. Demikianlah kebenaran Buddha dan kebenaran Siwa itu satu. Berbeda itu satu itu tidak ada Dharma yang mendua.

Dari kutipan itu bahwa anatara Buddha dan Siwa memang sulit untuk membedakannya. Dua yang berbeda namun telah terjalin menjadi satu kesatuan. Paralelisme tersebut ada pada tatanan metafisika, yang selanjutnya berkembang menjadi bentuk-bentuk fisik yang membentuk kebudayaan agama Siwa-Buddha di Indonesia. Dari kedua konsep paralel tersebut terjadi pada tujuan yang tertinggi yang diabstraksikan menjadi konsep Padmasana (Suamba, 2009:346).

Sinkretisasi sebagai fenomena sosial tentu dimengerti sebagai sikap yang bersikap akomodatif dalam mencari bentuk-bentuk yang lebih cocok dengan jalan mengikuti perkembangan zaman serta kebutuhan setempat. Ciri karakteristik kebudayaan Bali yang fleksibel, punya daya adaptasi yang tinggi, dibarengi dengan adanya kreatifitas dari pendukungnya maka setiap persinggungan kebudayaan tidak akan menimbulkan konflikkonflik budaya. Akan tetapi persinggungan budaya dengan pihak luar dari manapun datangnya dengan lokal-genius Bali yang punya adaptasi yang tinggi dengan tingkat fleksibelitas dan kelenturan yang tinggi pula, akan diramu untuk bertumbuh, berkembang dalam keselarasan, kesatuan dan menuju pada harmoni.

Tidak jauh berbeda pendapat ahli budaya Ramseyer yang mengutarakan karakter Kebudayaan Bali dan Indonesia asli bercirikan tetap bertahan, penuh perhatian, tampil bersatu, tetapi juga mendekati dunia luar. Contoh nyata dapat ditemukan pada Pura Kebo 
Edan di Desa Pejeng Gianyar. Pura ini adalah suatu versi Bali dari Candi pemujaan Kalacakra di Singasari. (Diartha Nida, 2003:18).

Kertanegara terkenal dengan ajaran Madhawa Tantra Rahasya, sehingga agama kerajaan Singasari mengarah pada Bherawa. Menurut sekte ini upacara-upacara dan persembahyangan keagamaan disertai dengan korban binatang dan menggunakan minuman keras, terutama persembahyangan pada kala. Di Bali sampai sekarang tradisi ini ditemukan pada upacara mecaru atau upacara tawur.

Sinkretisasi Siwa-Buddhadi Bali yang menumbuhkan harmoni antara paham Siwaismedan Buddhisme bahkan di pulau Jawa kepercayaan ganda yang khas dengan ciri pemujaan Dewa Ganda Harihara dikenal sebagai titik kulminasi sinkretisasi Siwa-Buddha.

Sinkretisasi sedemikian di Jawa adalah sebagai akibat dari pengaruh Bhagawatisme baik terhadap Siwaisme maupun terhadap Buddhisme. Maka lambat laun kedua ajaran itu dalam tujuannya sedikit sekali berbeda satu dari yang lain sehingga bagi seorang penganut yang saleh praktis tidak perlu lagi ada perbedaan antara jalan itu yang keduanya mengantarkan kepada kebebasan yang terakhir yaitu menajadi satu dalam Siwa yang adalah Buddha, jadi sesungguhnya menjadi Siwa-Buddha.

Dalam Lontar Candra Bherawa sinkretisme Siwa-Buddha telah nampak bahwa raja Yudhistira yang menganut paham Siwa dengan pendekatan Karma Sanyasa dengan keinginan mengajarkan rakyat Dewantara ajaran Karma Sanyasa, dengan membangun Sanggar Dengen, Sanggar Kabuyutan, dan Sad Kahyangan dan melakukan Panca Yandnya. Seperti dalam kutipan Lontar Candra Bherawa sebagai berikut: Muman puspitasca wrudah "Sajna Aji Sri Candra Bherawa, kami kinon de Sri Natha Krsna, umatur I jong Sri Bhupati, kuang Sri Maharaja inudesa de Sri Natha Krsna, eka paksa makarma sanyasa, hane sarira guhya swakirti aji ikang yoga sanyasa maka don Sri Aji sampun wruha ri suksma ning yoga sanyasa, ring loka drsta sinanggah kurang Sri Bhupati. Kamenanya haneng sakala, ikang yasa karma sanyasa Juga damel sang Prabhu, tan hana ng leneng widhiwidhana, tiniban puja mantra Samadhi, bondhan lwir ikang prthiwi, alpanamrta palapa ning bhumi, salwir ing phala bungkah phala gantung, padha hina sad rasanya kojar ing sastra. (Lontar Candra Bherawa, Lembar 15b-16a)

\section{Terjemahan:}

Ya ampun tuanku Raja Candra Bherawa, hamba diutus oleh Raja Krsna, untuk menyampaikan kepada duli tuanku, Raja, ada pun tuanku Raja diperintahkan oleh Raja Krsna supaya sama-sama melaksanakan ajaran Karma Sanyasa, apalagi tuanku sudah mengetahui betul tentang makna ajaran Yoga Sanyasa. Adapun di masyarakat tuanku Raja dianggap masih memiliki kekurangan, sebab dalam kehidupan nyata, tempat mengamalkan ajaran Karma Sanyasa. Hanya di dalam hati untuk memahami ajaran Yoga Sanyasa. Kalau ajaran Yoga Sanyasa yang tuanku Raja pegang teguh, meyakini tidak ada tanah yang disucikan, bercampur aduk namanya, sebab tidak pernah dibuatkan upacara, diberi doa mantra semadi, gersanglah jadinya tanah ini, hasil bumi kurag baik, segala umbiumbian, buah-buahan, tidak ada rasanya menurut ajaran suci. (Tim Penterjemah, 2004:56).

Dalam insiden diatas Sri Candra Bherawa menolak melaksanakan ajaran Karma Sanyasa, tetapi dalam insiden berkutnya justru Sri Candra Bherawa mengajarkan paham Siwa Tattwa kepada abdinya dengan mengajarkan Aji Bhuwana Sarira yang sisinya diambil dari Siwa Tattwa tepatnya diambil dari kitab Wraspati Tattwa,Jnana Siddhanta, Tattwa Jnana dan Bhuwana Kosa. Ajaran Bhuwana Sarira yang diajarkan oleh Sri Candra Bherawa kepada abdinya ialah tentang rahasia alam semesta (Macrocosmos) dan rahasia tentang tubuh manusia (Microcosmos) yang terdiri dari: (1) Sapta Patala, (2) Sapta Bhuwana, (3) Sapta Parwata, (4) Sapta Sagara, (5) Sapta Gni, (6) Sapta Sunya, (7) Dasa Bayu dan Nadi. Sebagaimana telah dijelaskan di depan. Pengetahuan tentang Aji Bhuwana Sarira 
tersebut di atas merupakan bentuk sinkretisma Siwa-Buddhadalam Lontar Candra Bherawa dalam bentuk Tattwa.

Sinkretisme Siwa-Buddha berikutnya nampak jelas dalam insiden perkawinan antara Raja Yudhistira setelah ia dapat menangkap roh Sri Candra Bherawa, dan menikahkan anaknya yang bernama Dyah Ratna Sasangka. Sri Candra Bherawa dengan senang hati mengawinkan putrinya yang bernama Dyah Ratna Sasangka dengan Raja Yudhistira. Berikut ini pernyataan raja Yudhistira dalam perkawinannya dengan Dyah Ratna Sasangka.

Ksatiyah hartvasca vitaya

Ling Sri Dewantara, Sajna Aji Maharaja Dharmaputra, pahlawan ta angen-angen Parameswara, apa hana punagi mami ri kita prabhu, i Sang kumawruhi swacitta mami, hana putri mami, Ni Ratna Sasangka ngaran iki, wirupa mudha duryasam astamyam tuhwasih Parameswara, wenang pinaka padyargha Sang Bhupati, ngimpunaken jong Bhupati, tumut waraha ta ring paramartha ning pariwara, hetunyan wruha ri gati-gati ning, karma sanyasa, nganutaken sadede singgih parameswara. (Lontar Candra Bherawa, Lembar 28a-28b).

\section{Terjemahan:}

Ksatiyah hartvasca vitaya

Berkatalah Raja Yudhistira: "Daulat ayahanda Raja Candra Bherawa, janganlah ayahanda khawatir, terhadap sangkaan ayahanda, aku meminta putrimu, sebagai sarana panutan ajaran Siwa Buddha pada ayahanda, sama-sama tidak bisa dipisahkan, sama-sama bisa saling mengisi, bagaikan bersatunya Atma dengan Dewa, ibarat menyatunya pikiran dengan pandangan, bagaikan siang dan malam hakikatnya. (Tim Penterjemah. 2004 :74).

Perkawinan antara Raja Yudhistira dengan Dyah Ratna Sasangka merupakan puncak dari paham Siwa-Buddha dalam Lontar Candra Bherawa. Perkawinan itu mengakibatkan timbulnya perdamaian di kedua negeri, yaitu negeri Hastinapura dan negeri Dewantara.
Kedua negeri itu mencapai puncak kejayaan di bawah naungan paham Siwa-Buddha. Kisah perkawinan antara Raja Yudhistira dengan Dyah Ratna Sasangka mirip dengan perkawinan antara Rakai Pikatan yang menganut paham Siwa dengan Pramodha Wardani yang menganut paham Buddha. Perkawinan itu dapat mewujudkan perdamaian di negeri Mataram Kuno dan melahirkan peradaban Hindu terbesar dan terindah di dunia, yaitu Candi Borobudur (Buddha) dan Candi Prambanan (Siwa). Kedua candi-candi agung itu merupakan bukti kebenaran Siwa-Buddha di tanah Jawa dan sekaligus sebagai bukti sinkretisme SiwaBuddha di kerajaan Mataram Kuno.

Ajaran Siwa-Buddha saling memberikan pengaruh sehingga terjadi hubungan yang erat dan kekeluargaan. Dalam Lontar Candra Bherawa hubungan tersebut ditegaskan kembali bahwa kedua ajaran tersebut bersumber dari sumber yang sama. Siwa-Buddha merupakan simbol dari dunia atas dan dunia bawah atau Sakala-Niskala. Hal tersebut dapat dilihat dalam prosesi ritus yajna di Bali, yang mana kedua pendeta Siwa dan Buddha mewakili aspek tersebut. Pendeta Siwa disimbolkan dengan alam Niskala atau Bapa Akasa, dan pendeta Buddha disimbolkan dengan alam Sakala, yakni Ibu Pertiwi. Bertemunya Bapa Akasa dan Ibu Pertiwi, maka terjadilah penciptaan. Sebagaimana Samkya Darsana menjelaskan bahwa duan aspek tersebut merujuk pada aspek Purusa sebagai unsur kejiwaan dan Prakerti sebagai unsur kebendaan. Kedua unsur tersebut mengalami perjumpaan, maka timbulah penciptaan alam semesta beserta dengan isinya (Maswinara,1999:46).

Berdasarkan pada hal tersebut, dalam pelaksanaan upacara besar di Bali kedua pendeta, yaitu pendeta Siwa dan Buddha turut ambil bagian dan hal ini dipandang tidak sempurna upacara yang dilakukan tanpa kehadiran dari kedua pendeta tersebut. Siwaisme dan Budhisme sebagai agama-agama negara yang berdampingan dan diakui, mantra yang dipergunakan oleh Pendeta Buddha juga digunakan oleh Pendeta Siwa seperti misalnya Sapta gangga, Surya-Stawa (Goris,1986:14-15). Kutipan berikut merupakan cerminan dari kedua konsep yang berbeda tersebut namun 
keduanya mempunyai sumber yang sama.

Sebagaimana diketahui bahwa masalah sinkretisme Siwa-Buddha sebagian besar diuraikan dalam teks-teks Buddha seperti Sutasoma, Sanghyang Kamahayanika, Bubhuksah dan sebagainya. Salah satu contohnya adalah Lontar Candra Bherawa. Pengawi naskah ini menceritakan tentang tokoh Yudhistira yang menganut ajaran Karma Sanyasa, dan Candra Bherawa yang menganut ajaran Yoga Sanyasa.

Dalam naskah disebut bahwa ajaran Karma Sanyasa berpusat pada pembangunan tempat suci, persembahyangan sesaji yang dikenal dengan Panca Yadnya, dan penyembahan kepada Dewa, sedangkan ajaran Yoga Sanyasa sebaliknya tidak ada tempat suci, tidak ada persembahan, dan tidak ada persembahan kepada Dewa. Yang dipuja adalah Sang Hyang Adi Buddha dengan mempelajari Aji Bajradhara. Tidak ada Dewa di luar (di tempat suci), tetapi ada di dalam diri, dan banyak persembahan hanya akan mengantar roh ke neraka. Karena itu, Dewa di dalam badah harus dipuja agar lepas dari sorga dan neraka, tidak terlahirkan kembali.

Ajaran Yoga Sanyasa yang dianut oleh Candra Bherawa (Tantra Buddha), seperti dijelaskan di atas, sama persis dengan ajaran tantra. tidak ada perbedaan prinsip antara tantra Hindu dan Buddha. Terlepas dari banyaknya perbedaan, secara esensial, tantrayana baik Buddisme maupun Hinduisme menekankan pada suatu prinsip fundamental bahwa kebenaran itu terletak pada badan manusia atau dengan kata lain, badan manusia adalah medium terbaik untuk merealisasikan kebenaran. Penekanan khusus pada pentingnya badan manusia sebagai kebenaran tertinggi, dan pada saat yang sama sebagai medium terbaik untuk merealisasikan kebenaran merupakan pendekatan yang membuat sadhana tantra berbeda dengan semua jenis sadhana lainnya. Walaupun demikian, baik Tantra Hindu maupun Buddha secara fundamental mempuyai ciri umum mengenai prinsip-prinsip teologi yang bersifat dualitas dalam non dualitas. Keduanya mengakui bahwa di dalam sifatnya yang fundamental, realitas non dualis yang tertinggi mempunyai dua aspek, yaitu negatif (nivrti) dan positif (pravrti), atau sifat-sifat statis dan dinamis. Kedua aspek dari realitas tersebut diwakili oleh
Siwa dan Sakti dalam agama Hindu, sedangkan dalam agama Buddha diwakili oleh Prajana dan Upaya (Suyata dan Karuna).

Konsep ajaran Siwa-Buddha inti sarinya adalah kemanunggalan. Sebagaimana Rema, (2011:24) menjelaskan bahwa inti sari ajaran Siwa-Buddha ialah ketika Parama Siwa dan Parama Buddha menjadi tujuan utama dari setiap makhluk yang ada di dunia ini, dan hanya makhluk yang sudah dapat melepaskan dirinya dari pengaruh dasendria yang dapat menemukannya, disebut nissreyasa atau nirbana. Seperti kutipan yang diajukan Sugriwa berikut yang dipetik dari kekawin Sutasoma, karya Mpu Tantular menyatakan sebagaiberikut: Kunang san wwang nissreyasa sira tatan siddhi ringulah. Ndatan puja tan yoga rinengepiran nisbhawa sada. Luput sangken bhawakrama pati hurip tan pangawara. Apan saksat sangkan paranika siracitya bhawana.

\section{Terjemahan:}

Adapun orang yang telah mencapai nissreyasa tidaklah terlalu panatik terhadap tingkahlaku. Tidak lagi mengunakan puja dan yoga dan tidak mengehendaki kemegahan dunia. Lepas dari pengaruh duniawi, hidup mati tidak menjadi halangan baginya. Karena ia seakan-akan berbadan Tuhan telah mencapai Nirbana.

Jadi yang dimaksud Siwa-Buddha adalah sebuah konsep kesatuan antara dua paham kepercayaan yang berbeda, yang lebur menjadi satu saling melengkapi satu dengan yang lainya. Sehingga menjadi agama yang sempurna bila dijalani dengan penuh disiplin oleh umatnya. inti pokok ajaran Siwa-Buddha itu adalah nirbana atau nissreyasa, bersatu dengan Paramartha Siwa Buddha. Orang yang telah mencapai nissreyasa tidaklah mempermasalahkan apakah melaksanakan puja atau yoga, juga tidak menghendaki kemegahan dunia. Lepas dari pengaruh duniawi, hidup mati tidak jadi halangan. Karena seakan-akan berbadan Tuhan telah mencapai nirbana. Tetapi tidak berlaku yang belum mencapai nirbana atau nissreyasa, yang belum mencapai harus giat 
mengusahakan diri agar mencapai nirbana dengan disiplin yang diajarkan Sang Buddha dan Siwa.

Kemesraan Siwa-Buddha dalam teks Arjuna Wiwaha digambarkan dengan sangat jelas oleh Yogi Agung yang bergelar Mpu Tantuar, pada manggala 1 stava 1 dengan menggunakan Wirama Sardula Wikridhita, terjemahanya sebagai berikut:

Om Sri Parwataraja Dewa, kehidupan mahluk hidup di dunia adalah sebuah arca Buddha tertinggi, dan yang disimpan di dalam pikiran para Yogi Siwa yang sempurna. Anda adalah madu bagi jiwajiwa agung (tetapi) racun bagi orangorang yang berbuat dosa, jelas seperti refleksi matahari di dalam air. Berguna bagi semua dunia. (Tim Penyusun, 2001:1)

Wirama ini mengingatkan kepada seorang raja yang bergelar Sri Parwataraja Dewa menyatakan, bahwa sejatinya antara Siwa dengan Buddha adalah setara. Hal ini digambarkan bahwa di dalam pikiran para Yogi Siwa, sejatinya berbeda himpunan keseluruhan mahluk hidup yang tiada lain adalah Arca Buddha. Dengan demikian antara Siwa dengan Buddha, tidak membutuhkan kata hubungan, namun ia adalah satu. Dengan demikian esensinya adalah satu. Artinya pada suatu kehidupan beliau dapat dipuja dengan esensi Siwa, demikian pula pada kehidupan yang lain disebut Buddha, yang sejatinya adalah tunggal.

Sepertinya kata yang paling tepat antara Siwa dengan Buddha adalah Siwa juga disebut Buddha, Buddha juga disebut Siwa. Dari segi kata, memang sebuah ketidak mungkinan untuk menyatukan dalam satu kata. Dari beberapa sumber yag telah dikutip di atas, telah menggunakan lambung penghubung (-) untuk menunjukan ketunggalannya. Namun kata yang paling tepat untuk menunjukan ketunggalan Siwa-Buddha yakni aksara suci OM. Pemahaman serta wujud ketunggalanya, sejatinya tidak cukup dari membaca, maupun mendengar dari orang lain. Sesungguhnya yang mampu membuktikanya dengan jalan pengalaman spiritual artinya tekun menjalankan Karma Sanyasa dan Yoga Sanyasa.
Apabila ajaran dalam Lontar Candra Bherawa di atas dianalisis menurut kerangka ajaran agama Hindu dan Buddha secara keseluruhan, maka Karma Sanyasa tidak lain dari ajaran eksoteris yang menekankan ajarannya ke luar badan, sedangkan ajaran Yoga Sanyasa dapat disejajarkan dengan ajaran esoterik yang memutuskan ajarannya ke dalam diri ke dalam badan. Secara tidak langsung, Lontar Candra Bherawa menempatkan Karma Sanyasa (eksoteris) lebih superior atau lebih unggul dari Yoga Sanyasa, sebagaimana terlihat dalam plot keberhasilan Yudhistira menangkap roh Candra Bherawa dan membawanya kembali ke Dewantara, dan adegan berikutnya dimana Candra Bherawa menyembah Yudhistira. Kecenderungan ini merupakan ritual dan upakara yajna dari ajaran Siwa-Buddhadi Bali.

Jadi, dalam arti khusus, agama Hindu yang dipraktikkan umat Hindu di Bali sampai saat ini adalah mazhab Siwa-Buddha. Sementara praktek Siwa-Buddha sebagai ajaran tantra hanya dilaksanakan oleh kalangan pendeta secara terbatas. Umat kebanyakan, bukan saja tidak mempraktikkan (Karena tergantung kepada pendeta) tetapi juga buta sama sekali dan tidak mengetahui ajaran-ajaran yang berkaitan dengan sekretisme Siwa-Buddha ini. Kenyataan ini dapat dimaklumi karena agama Hindu dan Buddha, baik di Indonesia maupun di India, pada mulanya berkembang di lingkungan kerajaan. Dalam pengertian ini, raja atas saran penasihat kerajaan (purohita) melaksanakan ajaran Siwa-Buddha, sedangkan rakyat hanya mengikui apa yang dilaksanakan atau yang diperintahkan oleh raja. Kondisi ini bertahan terus sampai kini dimana fenomena keagamaan secara keseluruhan, termasuk agama Hindu dan Buddha, sudah menjadi agama massa.

Memang ajaran yang dipraktikkan dalam tantra Siwa-Buddha disuplai oleh ajaran agama Buddha dan Hindu (Siwaisme) secara bersamasama. Dalam arti ini, mazhab tantra Buddha kadang-kadang dibedakan dari mazhab tantra Siwa. Tetapi dengan kecenderungan perkembangan terakhir di Bali, terutama setelah zaman kemerdekaan apa yang disebut SiwaBuddha tidak lain adalah subsistem dari agama Hindu. Secara formal, para pendeta Siwa maupun pendeta Buddha di Bali menganut 
agama Hindu sebagaiman tercantum dalam KTP mereka. Sejarahnya bisa ditelusuri setelah terbentuknya pemerintahan Indonesia pasca kemerdekaan di mana pemerintah menetapkan enam agama resmi Indonesia diantaranya: Hindu, Buddha, Islam, Katolik, Kristen, dan Konghucu. Setiap penduduk harus memilih salah satu dari enam agama tersebut. Menghadapi kenyataan ini, para pendeta Buddha dan pengikutnya di Bali tidak memilih masuk agama Buddha melainkan mengikuti rekan mereka para pendeta Siwa menjadi pemeluk agama Hindu.

\section{PENUTUP}

Lontar Candra Bherawa memiliki alur cerita yang mengisahkan tatkala ketika Kerajaan Hastinapura sudah di pimpin oleh Maharaja Yudhistira dan Catur Pandawa. Lontar Candra Bherawa menarasikan dua konsep ajaran ketuhanan yang berbeda, bagaimana tokoh Maharaja Yudhistira dari pihak Panca Pandawa yaitu dari Kerajaan Hastinapura, beliau mengajarkan kepada rakyatnya untuk selalu mengutamakan pembangunan tempat suci dan persembahan yadnya dan tidak lepas dari pelaksanaan Karma Sanyasa. Selalu di puja adalah Tuhan dalam manifestasinya menjadi Bhatara Siwa dan Para Dewata lainya untuk mencapai Nirguna (moksa). Sedangkan tokoh Maharaja Candra Bherawa memberikan ajaran kepada rakyat dari Kerajaan Dewantara, rakyatnya diperintahkan untuk selalu menjalankan nilai-nilai keagamaan yang diimplementasikan dalam diri tanpa menggunakan media tempat suci dan yadnya yang dipersembahkan kehadapan Tuhan, melainkan melaksanakan Yoga Sanyasa yaitu pencarian tuhan dalam diri sendiri. yang di Puja adalah Bhatara Buddha untuk mencapai Nirwana.

Konsep SinkretismeSiwa-Buddha merupakan kesatuan dari dua ajaran yang berbeda. Antara penekun ajaran Siwa dan penekun ajaran Buddha yang keduanya mengantarkan kepada kebebasan yang terakhir yaitu menajadi satu dalam Siwa dan Buddha.

\section{DAFTAR PUSTAKA}

Adnyana, Gd Agus Budi. 2013. Buddha Sakyamuni (Kisah Perjalanan Dan Melihat Kebijaksanaan). Denpasar: Vidia.

Diartha Nida.2003. Sinkretisme Siwa-Buddha di Bali. Denpasar: Bali Post.

Fananie,Zainuddin.2002. Telaah Sastra. Surakarta: Muhammadiyah University Press.

Kaelan. 2012. Metode Penelitian Kualitatif Interdisipliner. Yogyakarta: Paradigma.

Maswinara, I Wayan. 1999. Sistem Filsafat Hindu Sarva Darsana Samgraha. Surabaya: Paramita.

Rema, I Nyoman. 2011. Penyatuan Siwa-Buddha Pemikiran I Gusti Bagus Sugriwa Tentang Agama

Hindu Di Bali. Denpasar: IHDN Denpasar

Suarka, I Nyoman. 2012. Telaah Sastra Kakawin. Pustaka Larasan: Denpasar

Suamba, Putu, I.B. 2009. Siwa-Buddha Di Indonesia, Ajaran Dan Perkembangannya. Denpasar: PT. Mahabhakti

Tim Penerjemah. 2004. Tutur Candra Bherawa. Denpasar: Dinas Kebudayaan Provinsi Bali 